\title{
Milk and Urine Excretion of Polycyclic Aromatic Hydrocarbons and Their Hydroxylated Metabolites After a Single Oral Administration in Ruminants
}

\author{
D. Lapole,${ }^{*}$ G. Rychen,${ }^{* 1}$ N. Grova, ${ }^{*}$ F. Monteau, $†$ B. Le Bizec, $†$ and C. Feidt ${ }^{\star}$ \\ *UR AFPA, INPL-UHP-INRA, 2 avenue de la forêt de Haye, BP 172, 54505 Vandoeuvre-lès-Nancy, France \\ †LABERCA, ENV Nantes, Rte de Gachet, BP 50707, 44307 Nantes cx 3, France
}

\section{ABSTRACT}

The aim of this study was to establish the transfer of phenanthrene, pyrene, and benzo[a]pyrene and their major hydroxylated metabolites to milk and to urine after a single oral administration (100 mg per animal of each compound) in 4 lactating goats. Detection and identification of the analytes (native compounds, $1-\mathrm{OH}$ pyrene, 3-OH phenanthrene, 3-OH benzo[a]pyrene) were achieved using gas chromatography-mass spectrometry. Benzo[a]pyrene, phenanthrene, and pyrene were rapidly detected in the plasma stream, whereas 1-OH pyrene and $3-\mathrm{OH}$ phenanthrene appeared later in plasma. These data suggest that pyrene and phenanthrene are progressively metabolized within the organism. Recovery rates of pyrene and phenanthrene in milk over a 24 -h period appeared to be very low $(0.014$ and $0.006 \%$, respectively), whereas the transfer rates of their corresponding metabolites were significantly higher: $0.44 \%$ for $1-\mathrm{OH}$ pyrene and $0.073 \%$ for $3-\mathrm{OH}$ phenanthrene. Recovery rates in urine were found to be higher ( 1 to 10 times) than recovery rates in milk. The 1-OH pyrene was found to be the main metabolite in urine as well as in milk. Thus, as has been established for humans, 1-OH pyrene could be considered as a marker of ruminant exposure to polycyclic aromatic hydrocarbons. Because 1-OH pyrene and 3-OH phenanthrene were measured in milk (unlike their corresponding native molecules), metabolites of polycyclic aromatic hydrocarbons should be taken into consideration when evaluating the safety of milk. Benzo[a]pyrene and $3-\mathrm{OH}$ benzo[a]pyrene were (less than $0.005 \%$ ) transferred to milk and urine in very slight amounts. This very limited transfer rate of both compounds suggests a low risk of exposure by humans to benzo[a]pyrene or its major metabolite from milk or milk products.

Received December 1, 2006.

Accepted January 23, 2007.

${ }^{1}$ Corresponding author: Guido.Rychen@ensaia.inpl-nancy.fr
Key words: polycyclic aromatic hydrocarbon, milk, urine, metabolite, ruminant

\section{INTRODUCTION}

Polycyclic aromatic hydrocarbons (PAH) are usually found in the form of complex mixtures composed of compounds with 2 or more aromatic rings. These ubiquitous and persistent contaminants of the environment are formed during incomplete combustion and pyrolysis of organic matter. Human and industrial activities such as the processing of coal and crude oil, the combustion of natural gas, and vehicle traffic, disperse $\mathrm{PAH}$ into the environment and may contaminate fodder intended for lactating ruminants (Crepineau et al., 2003). Thus, according to their chemical and physical properties, PAH may migrate through the food chain.

Using labeled compounds, Grova et al. (2002) demonstrated that ${ }^{14} \mathrm{C}$ related to phenanthrene, pyrene, and benzo[a]pyrene was transferred to milk. These authors also showed that urine was an important excretion route for ${ }^{14} \mathrm{C}$ from $\mathrm{PAH}$. However, these authors did not distinguish native molecules from their metabolites. In fact, $\mathrm{PAH}$ are known to be metabolized in the organism (Raszyk et al., 1999), and part of the milk and urine excretion of the contaminants may be due to hydroxylated forms of PAH. Thus, the distribution of PAH and their metabolites in urine and in milk appears as a relevant question in terms of food safety. In other terms, is urine a major excretion route of $\mathrm{PAH}$ and their metabolites when compared with milk?

The aim of this study was to compare the transfer of phenanthrene, pyrene, and benzo[a]pyrene and their main hydroxylated metabolites to plasma, milk, and urine after a single oral administration in lactating goats.

\section{MATERIALS AND METHODS}

\section{Reagents and Chemicals}

Most reagents and solvents (acetic acid, acetonitrile, $n$-dodecane, cyclohexane, ethyl acetate, methanol, and 
toluene) were of analytical grade quality and were provided by Solvents Documentation Synthesis (Peypin, France) and Sigma Aldrich (St-Quentin-Fallavier, France). Helix pomatia juice was furnished by Biosepra (Villeneuve la Garenne, France). The solid-phase extraction columns (styrene-divinylbenzene copolymer resin, Envi Chrom P: 0.5 g) were from Supelco (StQuentin-Fallavier, France). The derivatization reagent $N$-methyl- $N$-(trimethylsilyl)trifluoroacetamide was purchased from Fluka (Buchs, Switzerland).

Standards references 3-hydroxyphenanthrene were from Chiron (Trondheim, Norway); phenanthrene, 1hydroxypyrene, and 2-hydroxyfluorene were obtained from Sigma Aldrich, and $d_{10}$-phenanthrene was from Interchim (Montluçon, France). Standard solutions were prepared at $1 \mathrm{mg} / \mathrm{mL}$ in toluene for 3-hydroxyphenanthrene and in methanol for phenanthrene. Working solutions were prepared monthly by 10 -fold successive dilutions at concentrations from 100 to $1 \mathrm{ng} / \mu \mathrm{L}$ and were stored at $-20^{\circ} \mathrm{C}$. The $\mathrm{d}_{10}$-phenanthrene and 2-hydroxyfluorene internal standard solutions were prepared at $1 \mathrm{ng} / \mu \mathrm{L}$ in methanol and in acetonitrile, respectively; 1-hydroxypyrene external standard solution was prepared at $1 \mathrm{ng} / \mu \mathrm{L}$ in acetonitrile.

\section{Animals and Treatment}

The animal protocol was in accordance with the general Guidelines of the Council of European Communities (1986, No. 86/609/CEE) and the French Animal Care Guidelines. Alpine goats (mean BW: $50 \pm 5 \mathrm{~kg}$ ) from the herd of the experimental station of the Ecole Nationale Supérieure d'Agronomie et des Industries Alimentaires (Laneuvelotte, France) were used. Ambient temperature was close to $22^{\circ} \mathrm{C}$, and natural light conditions prevailed. The lactating animals (third lactation, second month postpartum, average milk yield before the experiment of about $3 \mathrm{~L}$ ) were milked mechanically twice a day and adapted to the facilities for $10 \mathrm{~d}$; goats were fed with meadow hay, water, and mineral salt ad libitum and received a concentrate ration composed of dehydrated fodder beet, crushed corn, soybean meal, and dehydrated alfalfa to meet the nutritional requirements of the animals.

Four goats were fitted with 2 catheters: a temporary polyvinyl chloride intravenous catheter (Vialon, Becton Dickinson, le Pont de Claix, France) and a urinary polyvinyl catheter (Eschman Healthcare, West Sussex, UK). During the experiment, the intravenous catheters were rinsed with heparinized saline (50 IU of heparin per mL, Sanofi Choay, Gentilly, France).

The 3 selected PAH were phenanthrene, pyrene, and benzo[a]pyrene. Benzo[a]pyrene was selected as the reference compound of toxicity of PAH (US EPA, 1993, acta); pyrene was selected as the usual indicator of environmental contamination (Jacob and Seidel, 2002); and phenanthrene was selected because it is known to be the major compound excreted in cow milk and is strongly metabolized (Grova et al., 2005). Moreover, these $3 \mathrm{PAH}$ enable us to consider a decreasing number of benzene rings. One hundred milligrams [quantity chosen to ensure a satisfactory level of parent compounds and metabolites in all studied matrices and for the different time points of the kinetics (Grova et al., 2002, 2005)] of each PAH was mixed with $5 \mathrm{~mL}$ of cremophor EL (Fluka) and administered to the mouths of the animals by a syringe. After administration, the syringe was rinsed twice with $2 \mathrm{~mL}$ of cremophor EL.

Milk samples $(50 \mathrm{~mL})$ were collected before the PAH administration (control) and at 4 and $8 \mathrm{~h}$ for the first day. For the next $3 \mathrm{~d}$, milk samples were collected after milking every morning at $0800 \mathrm{~h}$ and evening at 1700 h. All milked samples were stored at $-20^{\circ} \mathrm{C}$ before analysis. Urine samples $(50 \mathrm{~mL})$ were collected before the $\mathrm{PAH}$ administration (control) and at 4 and $8 \mathrm{~h}$ for the first day. For the next $3 \mathrm{~d}$, the samples of urine were collected every morning at $0800 \mathrm{~h}$ and evening at 1700 h. All urine samples were stored at $-20^{\circ} \mathrm{C}$ before analysis. Plasma samples $(20 \mathrm{~mL})$ were collected before the PAH administration (control) and at 15, 30, and $45 \mathrm{~min}$ and $1,2,4,6,8,10,12$, and $16 \mathrm{~h}$ for the first day. For the next $3 \mathrm{~d}$, the samples of plasma were collected every morning at $0800 \mathrm{~h}$ and evening at $1700 \mathrm{~h}$ Plasma was centrifuged at $3,000 \times g(15 \mathrm{~min})$ and plasma collected in tubes. All plasma samples were stored at $-20^{\circ} \mathrm{C}$ before analysis.

\section{PAH Extraction}

Milk concentrations of native PAH (phenanthrene, pyrene, benzo[a]pyrene) and their major metabolites (1-OH phenanthrene, 1-OH pyrene, and 3-OH benzo[a]pyrene), were determined with a modified analytical procedure published recently (Grova et al., 2005). To hydrolyze conjugated metabolites, $150 \mu \mathrm{L}$ of purified Helix pomatia suc (Biosepra; preparation containing 25 units $/ \mu \mathrm{L}$ ) were added, and the samples were incubated for $16 \mathrm{~h}$ at $37^{\circ} \mathrm{C}$. Before $30 \mathrm{~min}$ of agitating the samples, internal standard $\left(d_{10}\right.$-phenanthrene, $d_{10}$-pyrene, $d_{12}$ perylene, 1-OH fluorene, and 1-OH chrysene; Interchim) as well as a mixture 50:50 (vol/vol; Solvents Documentation Synthesis) of cyclohexane/ethyl acetate were added. After centrifugation ( $15 \mathrm{~min}$ at $1,000 \times \mathrm{g})$, the supernatant was evaporated, and $6 \mathrm{~mL}$ of cyclohexane was added.

The Envi-Chrom P solid-phase extraction (styrenedivinylbenzene copolymer resin, Envi Chrom P: 0.5 g) column was conditioned with $5 \mathrm{~mL}$ of water, $5 \mathrm{~mL}$ of 
Table 1. Plasma kinetics of phenanthrene, pyrene, benzo[a]pyrene, and their major $\mathrm{OH}-$ metabolites after a single oral administration in ruminants $(\mathrm{n}=4$, mean and $\mathrm{SD})$

\begin{tabular}{|c|c|c|c|c|c|c|c|c|c|c|c|c|}
\hline \multirow{2}{*}{$\begin{array}{l}\text { Time after oral } \\
\text { administration, } \mathrm{h}\end{array}$} & \multicolumn{2}{|c|}{ Phenanthrene } & \multicolumn{2}{|c|}{$\begin{array}{c}\text { 3-OH } \\
\text { Phenanthrene }\end{array}$} & \multicolumn{2}{|c|}{ Pyrene } & \multicolumn{2}{|c|}{$\begin{array}{c}\text { 1-OH } \\
\text { Pyrene }\end{array}$} & \multicolumn{2}{|c|}{ Benzo[a]pyrene } & \multicolumn{2}{|c|}{$\begin{array}{c}\text { 3-OH } \\
\text { Benzo[a]pyrene }\end{array}$} \\
\hline & Mean & SD & Mean & SD & Mean & SD & Mean & SD & Mean & SD & Mean & SD \\
\hline 0.25 & 14.3 & 10.9 & 0.3 & 0.0 & 45.5 & 78.0 & 0.3 & 0.1 & 0.0 & 0.0 & 0 & 0.0 \\
\hline 0.5 & 8.3 & 1.2 & 0.3 & 0.0 & 124.4 & 70.0 & 0.3 & 0.1 & 0.0 & 0.0 & 0 & 0.0 \\
\hline 0.75 & 40.9 & 28.8 & 0.4 & 0.0 & 121.6 & 159.2 & 0.4 & 0.2 & 0.0 & 0.0 & 0 & 0.0 \\
\hline 1 & 12.7 & 9.9 & 0.4 & 0.1 & 156.5 & 9.7 & 0.5 & 0.4 & 0.0 & 0.0 & 0 & 0.0 \\
\hline 6 & 13.5 & 3.9 & 1.0 & 0.6 & 1.2 & 1.4 & 4.4 & 4.2 & 3.3 & 2.9 & 0 & 0.0 \\
\hline 8 & 14.4 & 8.8 & 1.7 & 1.2 & 2.1 & 1.4 & 4.3 & 0.6 & 4.1 & 2.9 & 0 & 0.0 \\
\hline 10 & 11.5 & 3.4 & 1.2 & 0.4 & 1.5 & 2.4 & 3.3 & 0.3 & 3.3 & 2.9 & 0 & 0.0 \\
\hline 12 & 9.7 & 14.1 & 7.1 & 1.1 & 3.2 & 0.7 & 3.8 & 0.6 & 1.0 & 0.8 & 0 & 0.0 \\
\hline 16 & 2.9 & 5.1 & 5.7 & 1.7 & 6.5 & 5.9 & 3.4 & 0.2 & 0.1 & 0.2 & 0 & 0.0 \\
\hline 23 & 0.0 & 2.3 & 4.0 & 2.6 & 5.1 & 4.9 & 3.5 & 1.0 & 0.0 & 0.0 & 0 & 0.0 \\
\hline 32 & 0.0 & 3.2 & 1.5 & 0.8 & 0.0 & 0.0 & 2.1 & 0.5 & 0.3 & 0.6 & 0 & 0.0 \\
\hline
\end{tabular}

methanol (Solvents Documentation Synthesis), and 5 $\mathrm{mL}$ of cyclohexane. The sample was applied in column, washed with $3 \mathrm{~mL}$ of cyclohexane, and the elution of PAH was realized with $12 \mathrm{~mL}$ of cyclohexane:ethyl acetate $(50: 50 ; \mathrm{vol} / \mathrm{vol})$. The samples were totally evaporated to dryness (at $40^{\circ} \mathrm{C}$ using $\mathrm{N}_{2}$ ), and $2 \mathrm{~mL}$ of cyclohexane and $2 \mathrm{~mL}$ of methanol:water (80:20; vol/vol) were added and mixed during $5 \mathrm{~min}$ at ambient temperature. Cyclohexane and the methanol:water phase were conserved for analyses. After centrifugation $(1,000 \times g$, $5 \mathrm{~min}$ ), the methanol:water phase was washed again with $2 \mathrm{~mL}$ of cyclohexane, centrifuged again $(1,000 \times$ $\mathrm{g}, 5 \mathrm{~min}$ ), and then the supernatant was added to the first cyclohexane phase. The cyclohexane phase, containing parent $\mathrm{PAH}$, was placed with $5 \mathrm{~mL}$ of $10 \% \mathrm{KOH}$ for $80 \mathrm{~min}$ at $90^{\circ} \mathrm{C}$ for saponification. To stop this process, $3 \mathrm{~mL}$ of water and $5 \mathrm{~mL}$ of cyclohexane were added. After centrifugation $(1,000 \times g, 5 \mathrm{~min})$, external standard $\left(\mathrm{d}_{12}\right.$-pyrene) was added and the supernatant was totally evaporated to dryness (at $40^{\circ} \mathrm{C}$ using $\mathrm{N}_{2}$ ). Twenty microliters of toluene was added to the solubilized PAH before injecting.

The methanol:water phase containing hydroxylated $\mathrm{PAH}$ was totally evaporated to dryness (at $40^{\circ} \mathrm{C}$ using $\mathrm{N}_{2}$ ), and $2 \mathrm{~mL}$ of water and $2 \mathrm{~mL}$ of ethyl acetate were added. After centrifugation $(1,000 \times g, 5 \mathrm{~min})$, an external standard ( $\mathrm{d}_{12}$-pyrene) was added to the supernatant. To conclude extraction, the supernatant was evaporated and samples derivatized with $20 \mu \mathrm{L}$ of $N$-methyl$N$-(trimethylsilyl) trifluoroacetamide (Fluka).

\section{PAH Analyses}

Quantitative analysis of $\mathrm{PAH}$ in milk, urine, and plasma was performed by GC-MS as previously described (Grova et al., 2005). Briefly, gas chromatogra- phy (Hewlett-Packard 6890, Palo Alto, CA) was coupled to a quadrupole MS (HP-5973) system. The split/ splitless injector was maintained at $250^{\circ} \mathrm{C}$; time of the splitless mode was set at $1.5 \mathrm{~min}$; and the injected volume was $2 \mu \mathrm{L}$. The column used to separate $\mathrm{PAH}$ and their metabolites was an OV-1 (Ohio-Valley) type $(30 \mathrm{~m} \times 0.25 \mathrm{~mm}$ i.d.; film thickness: $0.25 \mu \mathrm{m})$.

\section{Data Analysis}

Then ANOVA was used to compare the accumulated quantities and the distribution of $\mathrm{PAH}$ and their metabolites excreted in urine and milk for different periods ( 0 to $4 \mathrm{~h}, 0$ to $8 \mathrm{~h}$, and 0 to $24 \mathrm{~h}$ after oral administration of $\mathrm{PAH}$ ) as well as the transfer rates to milk and urine ( 0 to $24 \mathrm{~h}$ ) using the SAS statistical software (ANOVA, SAS Institute, Cary, NC). Student's $t$-test was used for comparison of the means.

\section{RESULTS}

\section{Kinetics of PAH and Metabolites in Plasma}

The kinetics of PAH and their metabolites in plasma are presented in Table 1. First, it appeared that benzo[a]pyrene and 3-OH benzo[a]pyrene were detected at a very low level in plasma. The other compounds could be detected, and a different behavior between the native compounds and their corresponding metabolites was observed. Concentrations of phenanthrene and pyrene were highest during the first $4 \mathrm{~h}$ after oral administration. For pyrene, the highest concentrations were found within the first $2 \mathrm{~h}$ (150 ng/mL of plasma), and these levels decreased quickly afterward. Phenanthrene concentration kinetics presented a slight increase during the first hour after oral administration (less than 50 $\mathrm{ng} / \mathrm{mL}$ ) and a continuous but slow decrease until $20 \mathrm{~h}$. 


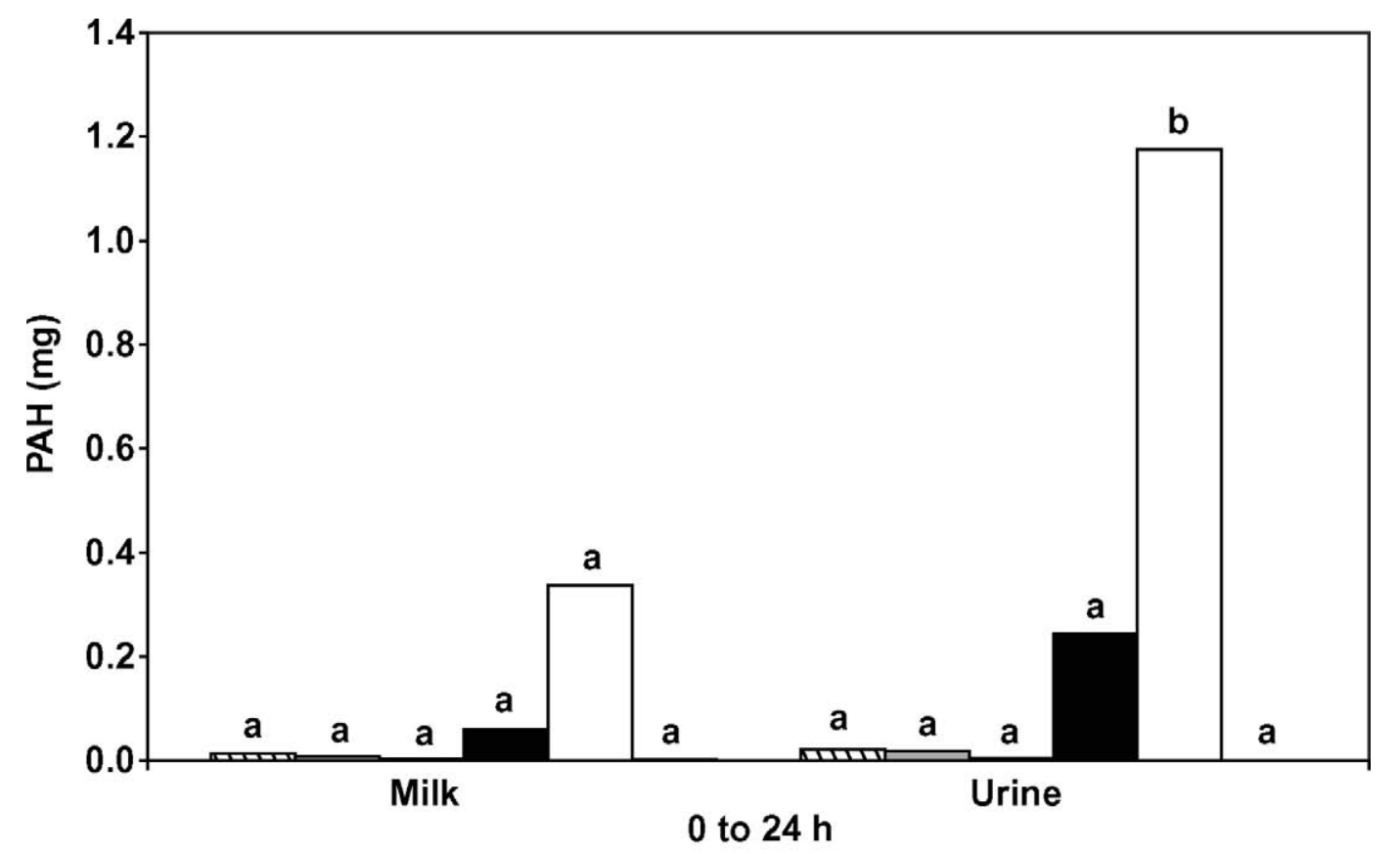

\section{QPhenanthrene}

-3-OH phenanthrene
口Pyrene

口1-OH pyrene
mBenzo[a]pyrene

¿3-OH benzo[a]pyrene

Figure 1. Polycyclic aromatic hydrocarbons (PAH) and OH-PAH excretion in milk and urine for 0 to 24 h. ${ }^{\mathrm{a}, \mathrm{b}} \mathrm{Mean}$ values with similar letters do not differ, $P>0.05$.

Their corresponding metabolite concentrations increased over time, and their appearance in the plasma compartment was delayed when compared with the native compounds: the highest concentrations were found after $5 \mathrm{~h}$. Concentrations of $1-\mathrm{OH}$ pyrene and $3-\mathrm{OH}$ phenanthrene in plasma were also found to be much lower (values below $10 \mathrm{ng} / \mathrm{mL}$ ) than the concentrations of the native molecules (the highest values were 157 $\mathrm{ng} / \mathrm{mL}$ for pyrene and $41 \mathrm{ng} / \mathrm{mL}$ for phenanthrene).

\section{PAH and Metabolites in Milk and in Urine}

Figure 1 indicates the cumulative excretion quantities of PAH and metabolites in milk and urine for the time period 0 to $24 \mathrm{~h}$ (Figure 1 ) after $\mathrm{PAH}$ oral administration. The parent compounds (phenanthrene and pyrene) appear to be present at low levels in milk and in urine regardless of the period considered. However, the quantities of $3-\mathrm{OH}$ phenanthrene and $1-\mathrm{OH}$ pyrene increased greatly over the periods studied with the highest excretion between 8 and $24 \mathrm{~h}$ after administration. Although the excretion of metabolites was highest after $8 \mathrm{~h}$, they appeared at significant levels in milk and in urine during the period of 0 to $4 \mathrm{~h}$. The $\mathrm{OH}$-metabolite quantities found in milk and in urine were generally higher than the parent compound quantities (Figure 1). Benzo[a]pyrene and 3-OH benzo[a]pyrene were found to be transferred to milk and urine in very small quantities.

A comparison of the transfer rates between the native compounds and the metabolites toward milk and urine (Table 2) showed low transfer levels of the native compounds and their major metabolites: these levels ranged from 0.002 to $0.03 \%$ for native compounds and from 0 to $1.175 \%$ for hydroxy-metabolites. The variance analysis carried out on accumulated quantities excreted in milk

Table 2. Percentage of ingested polycyclic aromatic hydrocarbons transferred to milk and urine during $24 \mathrm{~h}(\mathrm{n}=4)$

\begin{tabular}{lcc}
\hline Item & $\begin{array}{c}\text { Milk, } \\
\text { of ingested } \\
\text { dose }\end{array}$ & $\begin{array}{c}\text { Urine, } \\
\text { of ingested } \\
\text { dose }\end{array}$ \\
\hline Phenanthrene & $0.014^{\mathrm{a}}$ & $0.03^{\mathrm{a}}$ \\
Pyrene & $0.006^{\mathrm{a}}$ & $0.02^{\mathrm{a}}$ \\
Benzo[a]pyrene & $0.002^{\mathrm{a}}$ & $0.005^{\mathrm{a}}$ \\
3-OH Phenanthrene & $0.073^{\mathrm{a}}$ & $0.24^{\mathrm{a}}$ \\
1-OH Pyrene & $0.44^{\mathrm{b}}$ & $1.175^{\mathrm{b}}$ \\
3-OH Benzo[a]pyrene & $0.001^{\mathrm{a}}$ & $0^{\mathrm{a}}$ \\
\hline
\end{tabular}

${ }^{\mathrm{a}, \mathrm{b}}$ For each column, means followed by a similar letter do not differ, $P>0.05$. 
and urine revealed a significant compound effect $(P<$ 0.05 , Table 2): $1-\mathrm{OH}$ pyrene was found to be the main metabolite in milk and urine.

These results also indicate that the transfer of native compounds to milk or to urine was of similar low levels. When considering the different metabolites, the transfer rates in both matrices were quite different: $3-\mathrm{OH}$ benzo[a]pyrene was not detectable in urine and found to a very low level in milk (0.001\%). The other 2 metabolites showed higher transfer rates mainly in urine $(0.24$ to $1.175 \%)$, but also in milk (0.073 to $0.44 \%)$.

\section{DISCUSSION}

The results of this study provide relevant data on the transfer of PAH and their metabolites to milk and urine. In particular they demonstrate the specific behavior of benzo[a]pyrene, the ability of phenanthrene and pyrene to be metabolized, and finally the data indicate very low transfer rates.

\section{Specific Behavior of Benzo[a]pyrene and 3-OH Benzo[a]pyrene}

The results indicate that benzo[a]pyrene, considered as the reference toxicity compound, is detectable at very low levels in milk ( $7 \mathrm{ng} / \mathrm{mL}$; limit of detection: $1 \mathrm{ng} /$ $\mathrm{mL}$ ) and not detectable in urine (limit of detection: 1 $\mathrm{ng} / \mathrm{mL}$ ). Grova et al. (2002) also observed a very weak transfer to milk $(0.2 \%)$ of the radioactivity related to benzo[a]pyrene. The reduced presence of benzo[a]pyrene in its native form for both excretion routes could be explained by a strong metabolism of this compound and its biotransformation into various metabolites and particularly 1-OH benzo[a]pyrene and 3-OH benzo[a]pyrene (Buesen et al., 2002). However the absence of $3-\mathrm{OH}$ benzo[a]pyrene in the matrices "milk" and "urine" demonstrates that there is no excretion of benzo[a]pyrene in this hydroxylated form (sulfato or glucurono conjugated). All these observations suggest a very limited intestinal absorption of benzo[a]pyrene confirmed by an excretion rate of more than $80 \%$ of ${ }^{14} \mathrm{C}$ found in feces (Grova et al., 2002). Indeed, the plasma analysis confirmed that benzo[a]pyrene and 3-OH benzo[a]pyrene did not enter the organism in high levels. Buesen et al. (2003) and Cavret and Feidt (2005) also observed a small intestinal transfer of benzo[a]pyrene. Their experiments on the transfer of benzo[a]pyrene in Caco-2 cells demonstrated a strong interaction between benzo[a]pyrene and the cytochrome P450 system (Buesen et al., 2003; Cavret and Feidt, 2005). Indeed, the benzo[a]pyrene has a great potential of cytochrome $\mathrm{P} 450$ induction (Bols et al., 1999) because of its size (5 benzene rings). Other studies undertaken in the rat (Van de
Wiel et al., 1993) also showed that the majority of benzo[a]pyrene was not absorbed but was found in feces. Furthermore, a study on workers exposed to PAH (Waidyanatha et al., 2003) showed that unlike naphthalene, pyrene, phenanthrene, and their major metabolites, benzo[a]pyrene was not found in urine. Our results are in agreement with these data and clearly indicate that benzo[a]pyrene transfer from the intestine to the milk is very limited.

\section{Biotransformation of Phenanthrene and Pyrene}

Phenanthrene and pyrene appeared very quickly in the plasma stream (between 0 and $0.25 \mathrm{~h}$ ). The highest concentrations of phenanthrene $(50 \mathrm{ng} / \mathrm{mL})$ and pyrene (150 ng/mL) were reached at $45 \mathrm{~min}$ and $1 \mathrm{~h}$, respectively. The kinetics of $1-\mathrm{OH}$ pyrene and $3-\mathrm{OH}$ phenanthrene in plasma were quite different from the native compounds with highest concentrations found at 6 and $12 \mathrm{~h}$, respectively. These data suggest that phenanthrene and pyrene are mainly absorbed in their native form and progressively metabolized within the organism. Indeed, PAH are known to be heavily hydroxylated by cytochrome P450 mainly in the liver (Werck-Reichhart and Feyereisen, 2000; Roos, 2002).

The parent compounds (phenanthrene and pyrene) appear to be present in very low levels in milk and in urine after $24 \mathrm{~h}$. The $3-\mathrm{OH}$ phenanthrene and the 1$\mathrm{OH}$ pyrene quantities increased over the studied period. At $24 \mathrm{~h}, 1-\mathrm{OH}$ pyrene quantities in urine were significantly higher than all the other compounds. When compared with data in plasma, these results suggest a very strong biotransformation of the $2 \mathrm{PAH}$ by the organism as was suggested by Jacob and Grimmer (1996) and finally an excretion of the metabolites into milk or into urine.

\section{Rate of Transfer}

The rates of transfer to milk did not show a strong difference between phenanthrene and pyrene $(0.014$ and $0.006 \%$, respectively; Table 2). For the metabolites studied, $0.44 \%$ of 1-OH-pyrene was transferred to milk after $24 \mathrm{~h}$ and only $0.073 \%$ for $3-\mathrm{OH}$ phenanthrene, even though this metabolite is the main metabolite of phenanthrene found in milk (Grova et al., 2005). This difference between the 2 compounds may be explained by the reduced number of metabolites of pyrene $(2-\mathrm{OH}$ pyrene and 1-OH pyrene). Furthermore, 1-OH pyrene has been suggested to be a marker of exposure to $\mathrm{PAH}$ (Strickland and Kang, 1999).

Concerning the recovery rates in urine, these results complement previous data (Grova et al., 2002). Indeed, $\mathrm{PAH}$ are mainly transferred to urine in the form of 
metabolites, which represent for $3-\mathrm{OH}$ phenanthrene and 1-OH pyrene, respectively, 8 and 58 times the levels of the parent compounds. Urine would be, as is the case for humans (Strickland and Kang, 1999), a good indication matrix to determine the animal exposure to $\mathrm{PAH}$ by measuring $1-\mathrm{OH}$ pyrene concentrations.

Although the excretion of metabolites was generally higher in urine than in milk, the metabolite ratio of milk:urine is close to $36 \%$, as is shown in Table 2. This result suggests that urine excretion is a major (Withey et al., 1991; Bouchard and Viau, 1998; Lafontaine et al., 2000) but not the only excretion route for PAH and their metabolites in ruminants. Therefore, the level of metabolites in milk should also be taken into consideration.

Last, it is very interesting to note that even if lactating animals are exposed to high PAH quantities (100 $\mathrm{mg} / \mathrm{PAH}$ ), only a small percentage of native compounds will be found in milk $(0.014 \%$ of phenanthrene, 0.006 of pyrene, and $0.001 \%$ of benzo[a]pyrene). The PAH transfer to milk appeared to be much lower than the transfer of 2.3.7.8-tetrachlorodibenzo- $p$-dioxin, for example (Grova et al., 2002). This weak milk transfer rate suggests a low risk of contamination of the dairy food chain by PAH. The transfer of metabolites raises more questions, in particular because of the lack of information concerning their toxicity.

\section{CONCLUSIONS}

This study provides original data on the transfer of $\mathrm{PAH}$ and their metabolites to milk and urine. It particularly demonstrates the specific behavior of benzo[a]pyrene and 3-OH benzo[a]pyrene, with very low transfer rates to milk (less than $0.001 \%$ ). This very weak milk transfer rate of both compounds suggests a low risk of exposure by humans to benzo[a]pyrene or its major metabolite in milk and milk products. Indeed, benzo[a]pyrene is the only $\mathrm{PAH}$ compound that is commonly analyzed in food materials.

The second main result concerns 1-OH pyrene, which was found to be the main metabolite in urine as well as in milk. Thus, as has been established for humans, 1$\mathrm{OH}$ pyrene could be considered as a marker of ruminant exposure to $\mathrm{PAH}$. Because $1-\mathrm{OH}$ pyrene and $3-\mathrm{OH}$ phenanthrene were significantly detected in milk (unlike their corresponding native molecules), metabolites of PAH should be taken into consideration when evaluating the safety of milk.

\section{REFERENCES}

Bols, N. C., K. Schirmer, E. M. Joyce, D. G. Dixon, B. M. Greenberg, and J. J. Whyte. 1999. Ability of polycyclic aromatic hydrocarbons to induce 7-ethoxyresorufin-o-deethylase activity in a trout liver cell line. Ecotoxicol. Environ. Saf. 44:118-128.

Bouchard, M., and C. Viau. 1998. Urinary and biliary excretion kinetics of 1-hydroxypyrene following intravenous and oral administration of pyrene in rats. Toxicology 127:69-84.

Buesen, R., M. Mock, H. Nau, A. Seidel, J. Jacob, and A. Lampen. 2003. Human intestinal Caco-2 cells display active transport of benzo[a]pyrene metabolites. Chem. Biol. Interact. 142:201-221.

Buesen, R., M. Mock, A. Seidel, J. Jacob, and A. Lampen. 2002. Interaction between metabolism and transport of benzo[a]pyrene and its metabolites in enterocytes. Toxicol. Appl. Pharmacol. 183:168-178.

Cavret, S., and C. Feidt. 2005. Intestinal metabolism of PAH: In vitro demonstration and study of its impact on PAH transfer through the intestinal epithelium. Environ. Res. 98:22-32.

Crepineau, C., G. Rychen, C. Feidt, Y. Le Roux, E. Lichtfouse, and F. Laurent. 2003. Contamination of pastures by polycyclic aromatic hydrocarbons (PAHs) in the vicinity of a highway. J. Agric. Food Chem. 51:4841-4845.

Grova, N., C. Feidt, C. Crepineau, C. Laurent, P. E. Lafargue, A. Hachimi, and G. Rychen. 2002. Detection of polycyclic aromatic hydrocarbon levels in milk collected near potential contamination sources. J. Agric. Food Chem. 50:4640-4642.

Grova, N., C. Feidt, C. Laurent, and G. Rychen. 2002. [14C] Milk, urine and faeces excretion kinetics in lactating goats after an oral administration of $\left[{ }^{14} \mathrm{C}\right]$ polycyclic aromatic hydrocarbons. Int. Dairy J. 12:1025-1031.

Grova, N., F. Monteau, B. Le Bizec, C. Feidt, F. Andre, and G. Rychen. 2005. Determination of phenanthrene and hydroxyphenanthrenes in various biological matrices at trace levels using gas chromatography-mass spectrometry. J. Anal. Toxicol. 29:175-181.

Jacob, J., and G. Grimmer. 1996. Metabolism and excretion of polycyclic aromatic hydrocarbons in rat and in human. Cent. Eur. J. Public Health 4:33-39.

Jacob, J., and A. Seidel. 2002. Biomonitoring of polycyclic aromatic hydrocarbons in human urine. J. Chromatogr. B 778:31-47.

Lafontaine, M., J. P. Payan, P. Delsaut, and Y. Morele. 2000. Polycyclic aromatic hydrocarbon exposure in an artificial shooting target factory: Assessment of 1-hydroxypyrene urinary excretion as a biological indicator of exposure. Ann. Occup. Hyg. 44:89-100.

Raszyk, J., J. Neca, J. Salava, and J. Palac. 1999. A pilot study of 1-hydroxypyrene in the urine of pigs and cows. Vet. Med. (Praha) 44:359-363.

Roos, P. H. 2002. Differential induction of CYP1A1 in duodenum, liver and kidney of rats after oral intake of soil containing polycyclic aromatic hydrocarbons. Arch. Toxicol. 76:75-82.

Strickland, P., and D. Kang. 1999. Urinary 1-hydroxypyrene and other PAH metabolites as biomarkers of exposure to environmental PAH in air particulate matter. Toxicol. Lett. 108:191-199.

US EPA. 1993. Provisional guidance for quantitative risk assessment of polycyclic aromatic hydrocarbons. EPA/600/R-93/089, US Environmental Protection Agency, Office of Health and Environmental Assessment, Environmental Criteria and Assessment Office, Cincinnati, $\mathrm{OH}$.

Van de Wiel, J. A., P. H. Fijneman, C. M. Duijf, R. B. Anzion, J. L. Theuws, and R. P. Bos. 1993. Excretion of benzo[a]pyrene and metabolites in urine and feces of rats: Influence of route of administration, sex and long-term ethanol treatment. Toxicology 80:103-115.

Waidyanatha, S., Y. Zheng, and S. M. Rappaport. 2003. Determination of polycyclic aromatic hydrocarbons in urine of coke oven workers by headspace solid phase microextraction and gas chromatography-mass spectrometry. Chem. Biol. Interact. 145:165174.

Werck-Reichhart, D., and R. Feyereisen. 2000. Cytochromes P450: A success story. Genome Biology 1:reviews3003.1-3003.9.

Withey, J. R., F. C. Law, and L. Endrenyi. 1991. Pharmacokinetics and bioavailability of pyrene in the rat. J. Toxicol. Environ. Health $32: 429-447$. 